\title{
Evaluating the potential of rainfall product from Indian geostationary satellite for operational agromet advisory services in India
}

\author{
N. CHATTOPADHYAY ${ }^{1 *}$, S.S. VYAS ${ }^{1}$, B.K. BHATTACHARYA ${ }^{2}$ and S.CHANDRAS ${ }^{1}$ \\ ${ }^{1}$ Agricultural Meteorology Division, India Meteorological Department, Pune \\ ${ }^{2}$ Space Applications Centre, Ahmedabad \\ *Corresponding author Email: nabansu.nc@gmail.com
}

\begin{abstract}
Satellite remote sensing technology is increasingly gaining recognition as an important source of operational agro meteorological services. Spatial daily rainfall product from geostationary satellite is one of the important data source for quick evaluation of suitability of sowing conditions and other economically relevant agricultural operations (irrigation, fertilizer applications, spraying etc.) by farmers as well as disaster (drought, flood) warning causing crop loss and also to derive weather derivatives for crop insurance. In view of that a study was taken up to explore the use of satellite based rainfall data at different temporal scales. Under the present study, comparison has been made between Kalpana-1 high resolution $\left(0.25^{\circ} \times 0.25^{\circ}\right)$ rainfall estimates for four south-west monsoon months (June-September) in two contrasting monsoon periods of 2008 (normal) and 2009 (drought) with in situ measurements and forecast $\left(1^{\circ} \times 1^{\circ}\right)$ at nine AMFUs (Agro-Meteorological Field Units) in different agro climatic zones. Initial analysis show less correlation and large root mean square error (RMSE) of Kalpana-1 daily rainfall estimates with measurements and forecast. However, correlation was found to increase significantly from 60 to $80 \%$ over weekly to fortnightly scale with concomitant decrease in RMSE.
\end{abstract}

Key Words : Rainfall, geostationary satellite, india, agromet advisories

In order to decrease the vulnerability of agriculture to increasing climatic variability and ultimately to increase the crop production through weather forecast and agroadvisories, India Meteorological Department (IMD)/ Ministry of Earth Sciences (MoES) is operating an Integrated Agro-Meteorological Advisory Service (IAAS) at district level in India. Though agromet service is being provided efficiently at district level in the country, there is an urgent need to prepare and issue high resolution accurate weather forecast at block level. There isa need to strengthen the above mentioned services by monitoring, useof accurate data for a smaller region. The regular and nationalscale agro-meteorological monitoring requires retrieval or estimation of both core meteorological (e.g. rainfall. radiation) and land surface (e.g. vegetation index, leaf area index, land surface temperature, albedo etc.) variables to derive crop condition indicators to advise farming community on agricultural operations and management (Rijks et al., 1998). Ground-based observations from surface rain gauges, automatic weather stations weather radars, etc. provide accurate measurement of rainfall. However, in homogeneous coverage of these observations particularly over the unpopulated regions limits its applicability (Gairola et al., 2014).Also, there is a lack of high resolution and representative rainfall data for short, medium and long-term planning measures to minimise crop loss and agricultural risks. To fulfil these needs, satellite-based rainfall will be of great use as an important source for rendering operational agro meteorological services at smaller levels like block, village etc.Geostationary satellites provide data on a continuous basis and are supposed to be viable sources of information for weather monitoring in the tropics (Knapp et al., 2011).The diurnal observations and operational products from a suit of current (e.g. KALPANA-1, INSAT 3A, INSAT 3D) and future (INSAT - 3D-R) Indian geostationary satellites can be potentially utilized for agro-meteorological monitoring and value-added agro-advisories. Kalpana- 1 is the first dedicated meteorological satellite launched by the Indian Space Research Organization (ISRO) using Polar Satellite Launch Vehicle (PSLV) on 12th September2002. The satellite located at the central latitude $74^{\circ} \mathrm{E}$, carries a Very High Resolution scanning Radiometer (VHRR) for three band images: one in visible ( $0.55 \mathrm{ìm}-0.75 \mathrm{ìm})$, second in thermal infrared (10.5 ìm-12.5 ı̀m) and third in water vapor infrared (5.7ìm-7.1 ìm) bands with their ground resolutions of $2 \mathrm{~km}, 8 \mathrm{~km}$ and $8 \mathrm{~km}$, respectively. Its coverage in the eastwest direction ranges from $14^{\circ} \mathrm{E}$ to $134^{\circ} \mathrm{E}$. 


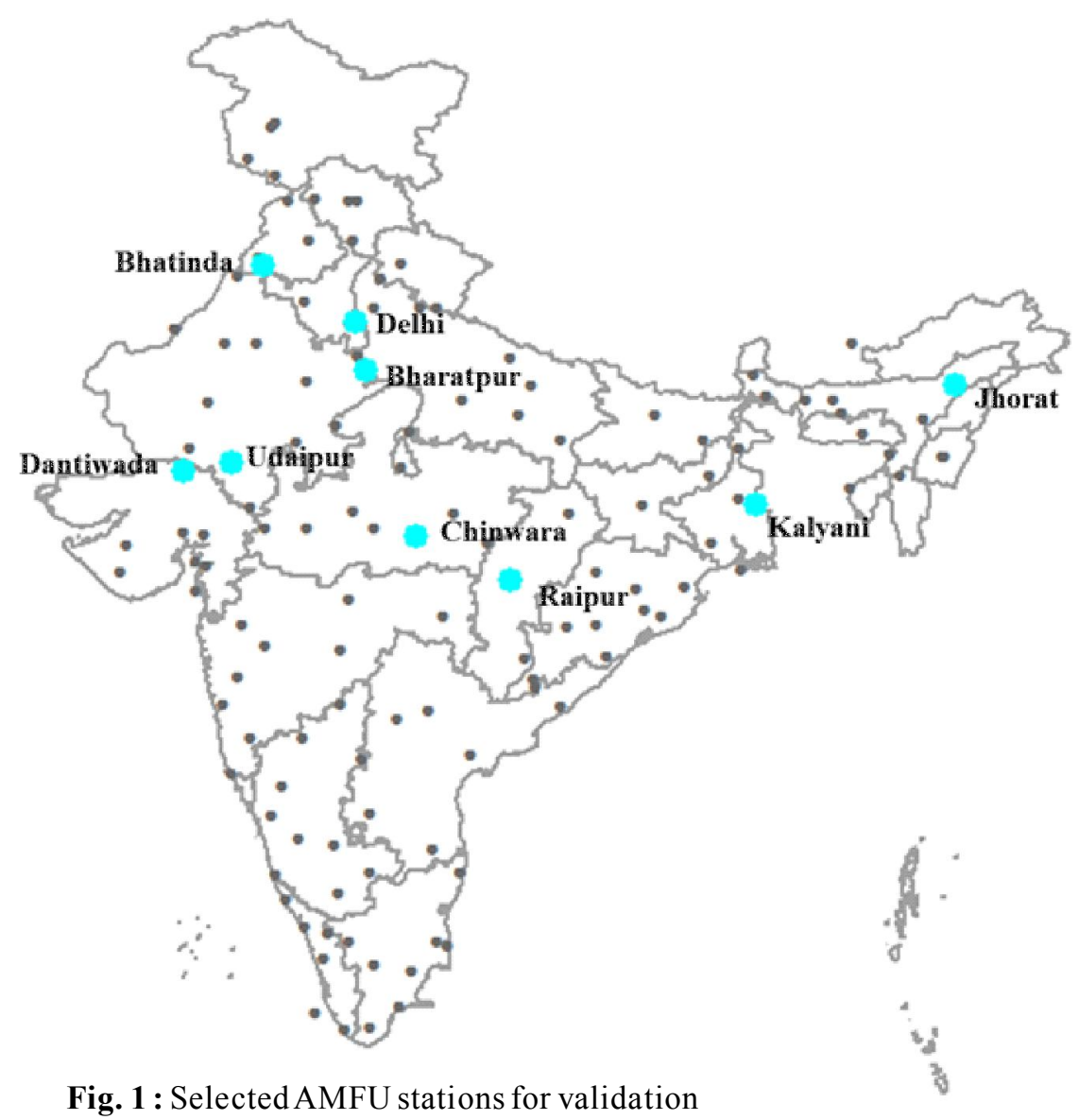

Use of meteorological products from such satellites will be extremely helpful to the proposed GKMS project to provide additional input for framing the block level Agromet Advisory. In this study, an attempt has been made to validate the Kalpana-1 rainfall data with observed, forecast and gridded rainfall data from selected stations in different agro-climatic zones in the country. The objective of the study was to evaluate the reliability of rainfall data from Indian geostationary satellite (e.g. KALPANA-1) for using it in agro met advisory services at different temporal scales.

\section{MATERIALS AND METHODS}

The validation of the potential of satellite rainfall for operational agro meteorology has been done by comparing the INSAT Multi-spectral Rainfall Algorithm(IMSRA) rainfall data for the months of South-West monsoon period (June to September) in the year of 2008 and 2009 with observed (OBS), gridded and quantitative rainfall forecast (PRED) data at different stations namely Bharatpur and Udaipur (semi-arid) in Rajasthan state, Bhatinda (sub tropic semiarid) in Punjab state, Chinwara (sub-humid) in Madhya Pradesh state, Dantiwada (semi-arid) in Gujarat state, New Delhi (semi-arid) in Delhi state, Kalyani (humid) in West
Bengal state, Raipur (sub-humid) in Chattishgarh state, Johrat (humid) in Assam state (Fig.1). Kalpana-1 high resolution $\left(0.25^{\circ} \times 0.25^{\circ}\right)$ rainfall estimates during four months(June-September) were acquired from MOSDAC (http://www.mosdac.gov.in). The daily rainfall product (K1VHR-IMR) from Kalpana-1 VHRR is generated through integration of instantaneous rain rate data at $0.25^{\circ}$ grid throughout a day. The half-hourly rainfalls are generated using INSAT Multi-spectral Rainfall Algorithm (IMSRA) (Prakash et al., 2010) which uses calibration of thermal infrared (IR) channel of Kalpana-1 with precipitation radar (PR) of Tropical Rainfall Measuring Mission (TRMM). The half-an-hourly rain from IMSRA was integrated for 24 hours to compute daily rainfall. The Kalpana- 1 rainfall estimates were further compared with the actual observed rainfall data, gridded data and forecast data in two contrasting south-west monsoon periods of 2008 (normal) and 2009 (drought) weekly, ten-day and fortnightlyrainfall summations of all the rainfall data were made. The gridded data used in this study were very high resolution $\left(0.50^{\circ} \times 0.50^{\circ}\right)$ daily rainfall data over the Indian region. These datasets of gridded daily rainfall is available to the research community for non-commercial purposes. This data set was developed 
Table 1: Correlation coefficient ( $r$ ) between RAIN and estimates from OBS, PRED and GRID centred at AMFUs for different summation periods

\begin{tabular}{|c|c|c|c|c|c|c|c|c|c|}
\hline \multirow[t]{3}{*}{ Stations } & \multicolumn{3}{|c|}{7 days } & \multicolumn{3}{|c|}{10 days } & \multicolumn{3}{|c|}{15 days } \\
\hline & OBS & PRED & GRID & OBS & PRED & GRID & OBS & PRED & GRID \\
\hline & vs.RAIN & vs. RAIN & vs. RAIN & vs. RAIN & vs. RAIN & vs. RAIN & vs. RAIN & vs. RAIN & vs. RAIN \\
\hline Bharatpur $\left(27.2^{\circ} \mathrm{N} 77.5^{\circ} \mathrm{E}\right)$ & 0.53 & 0.59 & 0.72 & 0.61 & 0.84 & 0.85 & 0.56 & 0.70 & 0.84 \\
\hline Bhatinda $\left(30.17^{\circ} \mathrm{N} 74.58^{\circ} \mathrm{E}\right)$ & 0.73 & 0.60 & 0.62 & 0.71 & 0.60 & 0.84 & 0.70 & 0.61 & 0.83 \\
\hline Chinwara $\left(22.5^{\circ} \mathrm{N} 78.93^{\circ} \mathrm{E}\right)$ & 0.65 & 0.74 & 0.76 & 0.74 & 0.85 & 0.91 & 0.68 & 0.82 & 0.89 \\
\hline Dantiwada $\left(24.32^{\circ} \mathrm{N} 73.0^{\circ} \mathrm{E}\right)$ & 0.80 & 0.80 & 0.77 & 0.73 & 0.75 & 0.85 & 0.70 & 0.86 & 0.87 \\
\hline $\operatorname{Delhi}\left(28.58^{\circ} \mathrm{N} 77.2^{\circ} \mathrm{E}\right)$ & 0.47 & 0.55 & 0.74 & 0.79 & 0.71 & 0.88 & 0.73 & 0.58 & 0.85 \\
\hline Johrat $\left(26.78^{\circ} \mathrm{N} 94.20^{\circ} \mathrm{E}\right)$ & 0.67 & 0.61 & 0.53 & 0.70 & 0.57 & 0.73 & 0.78 & 0.78 & 0.60 \\
\hline Kalyani $\left(23.40^{\circ} \mathrm{N} 88.52^{\circ} \mathrm{E}\right)$ & 0.66 & 0.62 & 0.65 & 0.83 & 0.61 & 0.76 & 0.54 & 0.65 & 0.78 \\
\hline Raipur $\left(21.60^{\circ} \mathrm{N} 81.60^{\circ} \mathrm{E}\right)$ & 0.70 & 0.62 & 0.74 & 0.75 & 0.65 & 0.77 & 0.68 & 0.62 & 0.75 \\
\hline Udaipur $\left(24.58^{\circ} \mathrm{N} 73.70^{\circ} \mathrm{E}\right)$ & 0.51 & 0.72 & 0.77 & 0.40 & 0.58 & 0.78 & 0.64 & 0.78 & 0.68 \\
\hline
\end{tabular}

AMFU: Agro-Met Field Unit

Table 2 :RMSE for varying periods of summation between satellite and station data.

\begin{tabular}{|c|c|c|c|}
\hline \multirow{2}{*}{$\begin{array}{l}\text { Summation } \\
\text { period }\end{array}$} & \multicolumn{3}{|c|}{ RMSE (mm) } \\
\hline & $\begin{array}{l}\text { OBS vs. } \\
\text { RAIN }\end{array}$ & $\begin{array}{c}\text { PRED vs. } \\
\text { RAIN }\end{array}$ & $\begin{array}{c}\text { GRID vs. } \\
\text { RAIN }\end{array}$ \\
\hline 7 Days & 34.49 & 33.96 & 30.26 \\
\hline 10 Days & 35.52 & 40.80 & 28.54 \\
\hline 15 Days & 59.24 & 46.30 & 38.99 \\
\hline
\end{tabular}

using quality controlled daily rainfall data archived at the National Data Centre, IMD, Pune from 6000 observatories, which measure rainfall occurred in the past $24 \mathrm{~h}$ ending 0830h Indian Standard Time (0300 UTC).A well tested interpolation method proposed by Shepard (1968) was used to interpolate the station data into regular grids of $0.5^{\circ} \mathrm{X}$ $0.5^{\circ}$. This method is based on the directional effects, weights and the distance between the station and the grid point (Rajeevan et al., 2005). Also the five days' multi-model ensemble forecast rainfall data is used in this study. These data were generated on weekly bases at IMD, New Delhi based on forecast products available from number models of India and other countries. These models includeT-254 model of NCMRWF, T-799 model of European Centre for Medium Range Weather Forecasting (ECMWF); United Kingdom Met Office (UKMO), National Centre for Environmental Prediction (NCEP), USA and Japan Meteorological Agency (JMA) (Attriet al., 2011). The product generated from the model has been value added and used in operational agroadvisory services.

\section{RESULTS AND DISCUSSION}

The present study is done with data from nine agro- climatic zones and four types of rainfall data viz. observed, predicted, satellite and gridded data. The satellite rainfall data proved to be in good correlation ( $r$ ) with AWS data over land upto 0.70 for daily rain estimates except orographic regions such as north-east and south-west India and 0.72 for monthly rainfall estimates (Prakash et al., 2010). The maximum correlation coefficients $(r)$ were found to be 0.80 , 0.83 and 0.78 when compared to OBS data, $0.80,0.84$ and 0.86 when compared with PRED estimates and these were 0.76 , 0.91 and 0.89 (Table 1 ) when compared with GRID estimates for varying periods (7,10 and 15 days) of summation.

The GRID and PRED estimates show maximum correlation in most of the cases with RAIN as compared to reported correlation with in situ point measurements from AWS (Prakash et al., 2009). The ' $r$ ' was found to increase with the increase in summation period from 7 days to 10 days for OBS, PRED and GRID estimates. In case of PRED estimates, it shows degradation with summation period over 15 days. The realized medium-range forecast at AMFU is valid only for 7 days to 10 days. Therefore, degradation in forecast quality beyond 10 days might deteriorate the ' $r$ '. In the case of the GRID data, there was an increase in ' $r$ 'values from 7 to 10 days of summation period while it remained more or less in the same range of $80-85 \%$ for the summation period of 10 and 15 days.

The ' $r$ ' of GRID when compared with RAIN recorded highest values for almost all the 9 stations. The stations in the semi-arid tract show higher correlation of GRID and RAIN data as compared to the stations in the humid, subhumid regions. The high values of ' $r$ ' were recorded for the Chinwara station over all the summation periods and low values of ' $r$ ' were recorded for Udaipur station. 


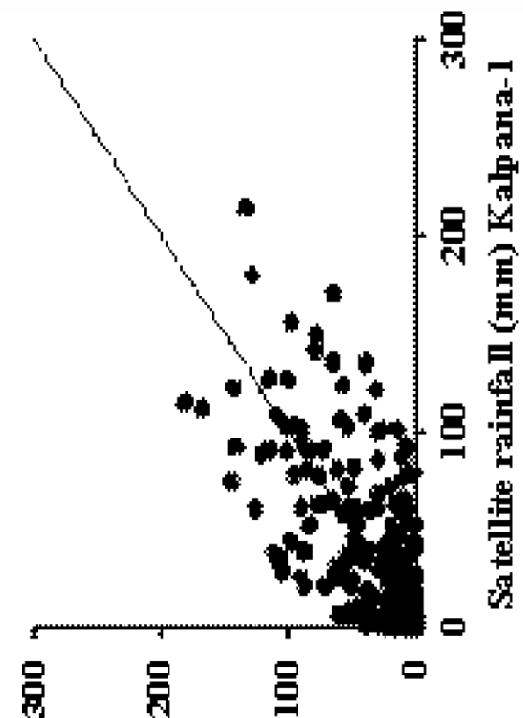

म11

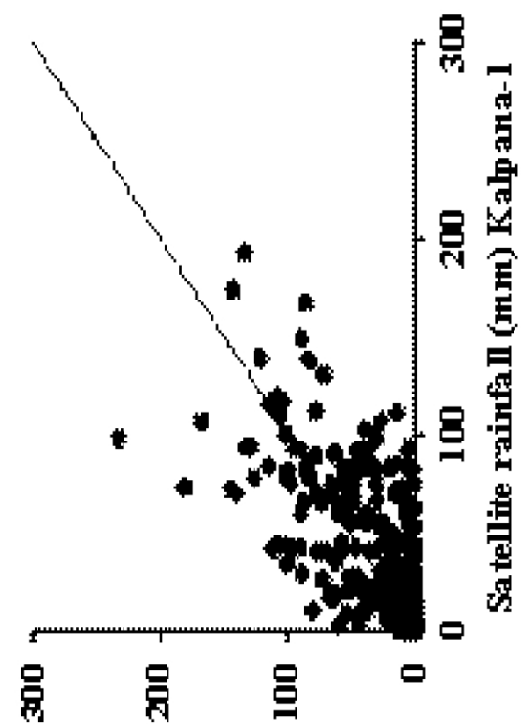

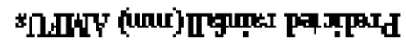

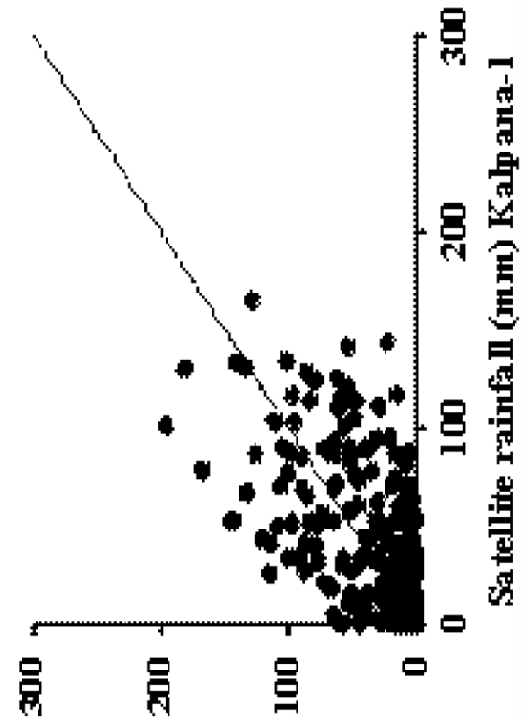

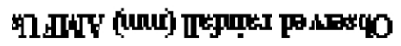

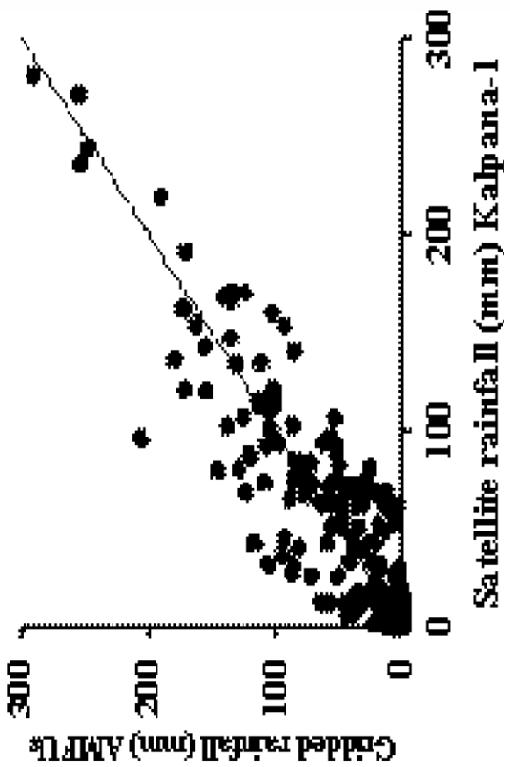

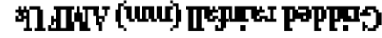

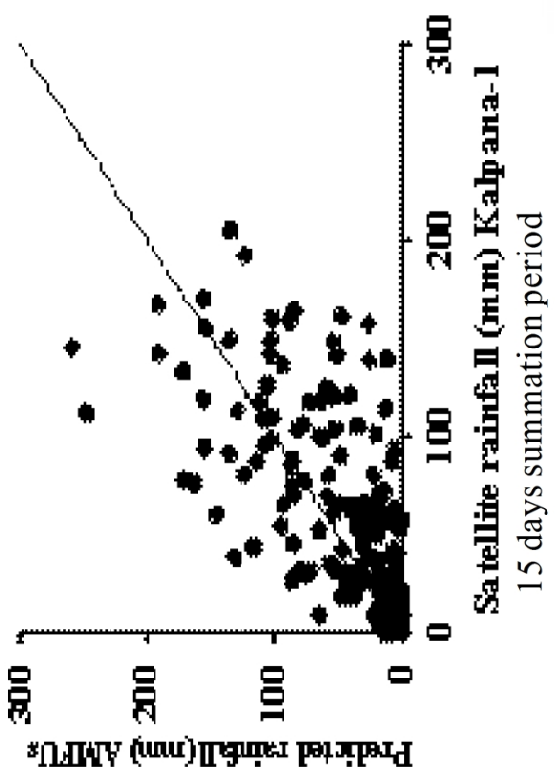

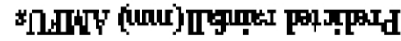

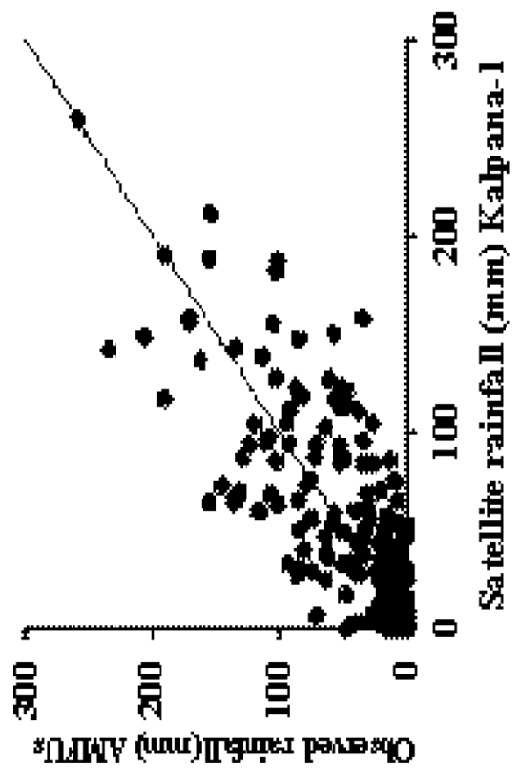

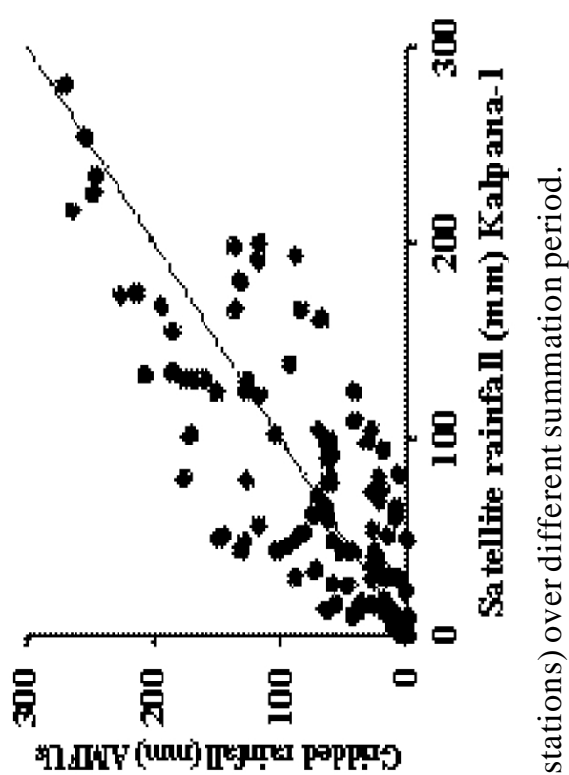

मी1

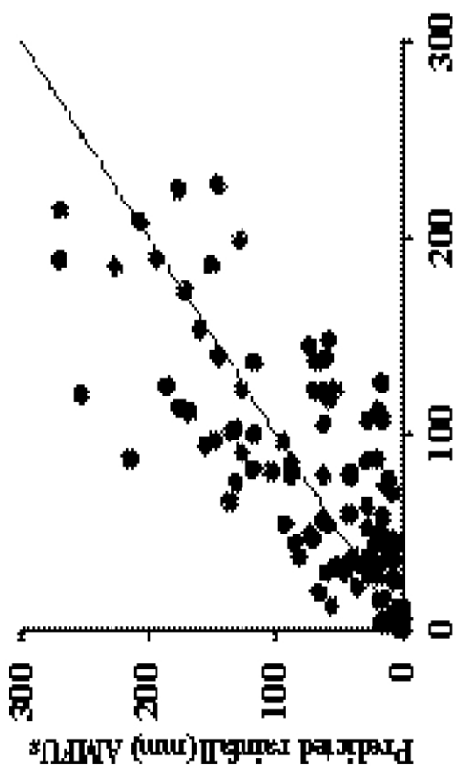

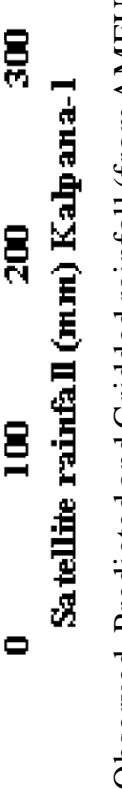

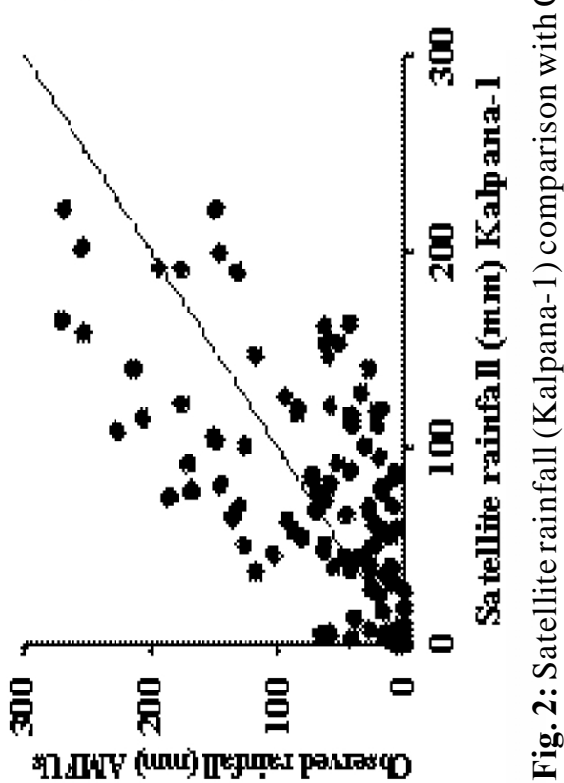


It is quite evident from the above comparison that the validation source, its scale representativeness, and quality play important roles while verifying the satellite-based rainfall estimates at different spatial resolutions. It can be inferred that the correlation coefficient generally increased as the summation period increased. The scatter plots of the OBS, PRED and GRID data with RAIN data pooled for all the nine stations is given over the summation periods of 7, 10 and 15 days in (Fig.2). The scatter plots of OBS and PRED with RAIN data show weak to moderate positive correlation over the summation periods from 7, 10 to 15 days. Whereas, scatter plots of GRID and RAIN data show a positive correlation for 7 and 15 day summation period and strongest correlation is observed over the 10 day summation period.

The root mean square error (RMSE) of estimates for varying periods ( 7 to 15 days) of summation of Kalpana-1 VHRR rainfall were compared with the pooled data of all the AMFU station data (Table 2). The RMSE were found to decrease when compared with OBS, PRED and GRID data. The RMSE were least for RAIN and GRID data for all the summation periods. The RMSE of 30.26, 28.54 and 38.99 $\mathrm{mm}$ were observed for the summation periods of 7,10 and 15 day respectively with GRID data.

\section{CONCLUSION}

Initial analysis presented poor correlation and large root mean square error (RMSE) for daily rainfall estimates from Kalapan-1 with measurements and forecast data. However, correlation was found to increase significantly from 60 to $80 \%$ over weekly to fortnightly summative basis with decrease in RMSEfor OBS rainfall, PRED data and GRID data. This study clearly brought out the following points : (a) Though error is high, better year-to-year consistency in Kalpana-1 rainfall estimates exists as compared to other sources of data; (b) The rainfall estimates from Indian geostationary satellites have more potential to be used on weekly to fortnightly summative basis than daily basis after bias correction with respect to all the AMFUs; (c) bias corrected gridded rain from geostationary satellite can be used as a check for evaluating the quality of gridded rainfall forecast and (d) better correlation was found between satellite rainfall with the 10 day summation gridded rainfall.This study can be extended to all agro-climatic zones by studying individual zone in the country.

\section{ACKNOWLEDGEMENT}

The authors would also like to thank National Climate
Centre (NCC), IMD Pune, for providing Predicted and Gridded rainfall ground station data and Meteorological Oceanographic Satellite Data Archival Centre (MOSDAC), Bopal Campus, SAC, for providing Kalpana -1 VHRR rainfall products.

\section{REFERENCE}

Attri S.D., Rathore L.S., Sivakumar M.V.K., Dash S.K. (2011). Challenges and Opportunities in Agrometeorology, (Eds), Springer-Verlag, Berlin Heidelberg 2011, 195-196.

Knapp, K.R.,Ansari, S., Bain, C.L., Bourassa, M.A., Dickinson, M.J., Funk, C., Helms, C.N.,Hennon, C.C.,Holmes, C.D., Huffman, G.J.,Kossin, J.P., Lee, H.T.,Loew, A.,Magnusdottir, G. (2011). Globally Gridded Satellite Observations for Climate Studies.Bulletin American Meteorol. Soc., 92(7) : 893-907, 10.1175/ 2011BAMS3039.1.

Gairola, R. M., Prakash, S., Bushair, M. T and Pal, P. K. (2014). Rainfall estimation from Kalpana-1 satellitedata over Indian land and oceanic regions. Current Sci., 107(8): 1275-1282.

Prakash, S., Mahesh,C, Mishra,A., Gairola, R. M., Varma,A. K., Pal,P.K. (2009).Combined use of Microwave and IR data for the study of Indian Monsoon Rainfall-2009, ISPRS Archives XXXVIII-8/W3 WorkshopProceedings: Impact of ClimateChange on Agriculture, 17-18 Dec 2009, SAC,Ahmedabad.

Prakash, S., Mahesh, C., Gairola, R. M., Pal, P. K. (2010).Estimation of Indian summer monsoon rainfall using Kalpana-1 VHRR data and its validation using rain gauge and GPCP data.Meteorol.Atmosph. Phys., 110: $45-57$.

Rajeevan, M., Pai, D.S., Rohilla, A.K. (2006).New statistical models for long-range forecasting of southwest monsoon rainfall over India.National Climate Centre Res. Report, No. 2/2006.

Rijks, D., Terres,J.M.,Vossen, P. (2009).ReportAgrometeorological applications for regional crop monitoring and production assessment.Joint research centre, European commission, EUR 17735 EN.

Shepard D.(1968).A two-dimensional interpolation functions for irregularly-spaced data. Proce \& ACM National Conference.517-524. 